\title{
Structure of Micro-nano WC-10Co4Cr Coating and Cavitation Erosion Resistance in NaCl Solution
}

\author{
Xiang Ding ${ }^{1} \cdot$ Xu-Dong Cheng ${ }^{1} \cdot$ Cheng-Qing Yuan $^{2} \cdot$ Jin Shi $^{2} \cdot$ Zhang-Xiong Ding $^{2}$
}

Received: 29 June 2016/Revised: 27 February 2017 / Accepted: 4 July 2017/Published online: 25 July 2017

(c) The Author(s) 2017. This article is an open access publication

\begin{abstract}
Cavitation erosion (CE) is the predominant cause for the failure of overflow components in fluid machinery. Advanced coatings have provided an effective solution to cavitation erosion due to the rapid development of surface engineering techniques. However, the influence of coating structures on CE resistance has not been systematically studied. To better understand their relationship, micro-nano and conventional WC-10Co4Cr cermet coatings are deposited by high velocity oxygen fuel spraying(HVOF), and their microstructures are analyzed by OM, SEM and XRD. Meanwhile, characterizations of mechanical and electrochemical properties of the coatings are carried out, as well as the coatings' resistance to CE in 3.5 wt $\% \mathrm{NaCl}$ solution, and the cavitation mechanisms are explored. Results show that micro-nano WC-10Co4Cr coating possesses dense microstructure, excellent mechanical and electrochemical properties, with very low porosity of $0.26 \pm 0.07 \%$ and extraordinary fracture toughness of $5.58 \pm 0.51 \mathrm{MPa} \cdot \mathrm{m}^{1 / 2}$. Moreover, the $\mathrm{CE}$ resistance of micro-nano coating is enhanced above 50\% than conventional coating at the steady CE period in 3.5 wt $\% \mathrm{NaCl}$ solution. The superior $\mathrm{CE}$ resistance of micronano WC-10Co4Cr coating may originate from the unique micro-nano structure and properties, which can effectively obstruct the formation and propagation of CE crack. Thus,
\end{abstract}

Cheng-Qing Yuan

120455684@qq.com

1 State Key Laboratory of Advanced Technology for Materials and Processing, Wuhan University of Technology, Wuhan 430070, China

2 School of Energy and Power Engineering, Wuhan University of Technology, Wuhan 430063, China a new method is proposed to enhance the CE resistance of WC-10Co4Cr coating by manipulating the microstructure.

Keywords Cavitation erosion resistance $\cdot$ Micro-nano structure $\cdot$ WC-10Co4Cr coating $\cdot$ HVOF

\section{Introduction}

Cavitation erosion (CE), which is the predominant cause for the failure of overflow components, can be frequently observed in fluid machinery such as ship propellers and rudder blades, the cylinder liners of marine diesel, turbine impellers and various pumps. Corrosive ocean environment will accelerate the cavitation damage of the overflow parts of ships and drilling platforms. CE has become the central technical problems of the fluid equipment, which threatens the safety of the equipment, reduces the efficiency and increases the cost $[1,2]$. Therefore, improving the CE resistance of the materials in fluid machinery has significant economic benefits.

The mechanism of cavitation erosion has not yet fully been understood, as it is influenced by multiple parameters, such as hydrodynamics, component design, service environment and material properties. Because CE occurs only on the surface of components, advanced surface engineering techniques have become the most effective approaches to solve CE problems [3, 4]. Several advanced surface engineering techniques, such as thermal spraying, plasma nitriding, chemical vapor deposition, physical vapor deposition, laser cladding, and hardening have been developed to modify the surface properties of component materials. Among them, thermal spraying methods, including arc plasma spraying (APS), detonation gun(DGun), and high velocity oxy-fuel spraying(HVOF) have 
been commercially applied on overflow components of fluid machinery to enhance the cavitation erosion resistance [5].

WC based cermet coatings are well-known for their outstanding wear resistance [6], which has drawn much attention in the research of $\mathrm{CE}$ resistant materials. WC-Co coatings, especially those with nanostructures, have already been successfully applied in a wide range of fluid machinery [7]. Compared with the WC-Co coatings, WCCoCr coatings possess higher strength and better corrosion resistance and are expected to have more excellent $\mathrm{CE}$ resistance in corrosive media like ocean environment [8].

WC particle size in WC based coatings significantly affects its microstructure and properties. Armstrongr [9] proposed that mechanical properties and wear resistance of the WC based coatings would generally increase with decreasing WC particle size. The studies of Ghabchi [10] and $\mathrm{Ma}$ [11], et al. showed that optimizing WC size and structure can improve the mechanical properties and wear resistance of HVOF sprayed WC based coatings. Scieska [12] and Li [13], et al. suggested that WC based cermet coatings with a high volume fraction of fine WC particles would exhibit high wear performance. Therefore, nanostructure WC based coatings have been extensively studied for the improvement of the microhardness and wear performance [14, 15]. Tillmann, et al. [16], reported sliding and rolling wear behavior of HVOF-sprayed nanostructured WC-12Co coatings. HONG, et al. [17], revealed cavitation erosion behavior and mechanisms of $\mathrm{HVOF}$ sprayed nanostructured WC-10Co4Cr coating in $\mathrm{NaCl}$ solution. The researches of Zhao [18] and Chen [19], et al. have demonstrated that the hardness and toughness of nanostructured materials can be improved simultaneously. But Dent [20] and Yang [21], et al. also revealed the decrease of fracture toughness of WC based coatings with decreasing the WC size because of decarburization of nano WC followed by the formation of unwanted carbides, such as $\mathrm{W}_{2} \mathrm{C}$, complex $\mathrm{Co}-\mathrm{W}-\mathrm{C}$, and metallic tungsten, which can also lower the mechanical properties of nanostructure WC based coatings. In order to prevent the decarburization of nano WC and reduce the cost of the nano coatings, Skandan [22] and Ji [23], et al. proposed a new kind of micro-nano WC based coating composed of nano and micro WC grain size, which is expected to obtain dense structure and excellent anti-cavitation performance. But, the structures, properties of micro-nano $\mathrm{WC}-\mathrm{CoCr}$ coating, e.g., hardness, fracture toughness and $\mathrm{CE}$ resistance in corrosive environment, have not been fully understood.

The deposition process is another important factor which influences the structures and properties of WC based cermet coatings. Among all the thermal spraying approaches, HVOF has high flame velocity and moderate flame temperature, which can minimize the decarburization of
WC to a low level. Therefore, HVOF is an ideal method to deposit micro-nano WC-CoCr cermet coatings [24, 25].

In this work, micro-nano and conventional WC10Co4Cr coatings (MC and CC) were deposited by HVOF. The microstructure, mechanical properties, electrochemical performance and $\mathrm{CE}$ resistance in $3.5 \mathrm{wt} \% \mathrm{NaCl}$ solution of the coatings were studied, and the cavitation mechanisms of the coatings were explored. The results can provide important reference for the design of $\mathrm{WC}-\mathrm{CoCr}$ anticavitation coatings in ocean environment.

\section{Experimental Procedure}

\subsection{Coating Preparation}

Micro-nano and conventional WC-10Co4Cr composite powders (MP and CP), produced by Ganzhou Achteck Tool Technology Co. Ltd, were sprayed on austenitic stainless steel AISI 316, and their characteristics are presented in Table 1. The WC-10Co4Cr coatings were deposited by JP8000 HVOF equipment using kerosene as fuel and oxygen as oxidant gas, and spraying parameters were optimized as shown in Table 2.

Prior to spraying, the substrate surface was cleaned with acetone and grit blasted with 60 mesh corundum. The thickness of the coatings was controlled in $450 \pm 20 \mu \mathrm{m}$. All the samples were ground and polished to an average surface roughness $R a \leq 0.02 \mu \mathrm{m}$ before any characterizations.

\subsection{Characterization}

The morphology and microstructures of the powders and the coatings were observed with VHX-2000 digital optical microscope(OM), and FEI Quanta 250 scanning electron microscope(SEM). Phase identification for the powders and the coatings was carried out by a D/max-2550 diffraction meter(XRD) using $\mathrm{Cu}-K_{\alpha}$ radiation with $\lambda=0.154 \mathrm{~nm}$.

Microhardness measurements were performed via HVS1000 microhardness tester at a load of $300 \mathrm{~g}$ for $15 \mathrm{~s}$. The porosity was measured with metallographic 200X photos captured by Axiovet 40 MAT metallographic microscope, followed by porosity calculation using IQ materials software. The fracture toughness $K_{c}$ was calculated according to the Wilshaw Eq. (1) [26] (the result was the average value of ten measurements), where $P, a$ and $c$ are the load of Huayin HV5 type Vickers hardness meter $(5 \mathrm{~kg})$, half the length of indentation diagonal and half the length of the crack, respectively.

$K_{c}=0.079 \frac{P}{a^{3 / 2}} \lg \left(\frac{4.5 a}{c}\right)$. 
Table 1 Characteristics of two WC-10Co4Cr composite powders

\begin{tabular}{lllllll}
\hline Powder No. & Powder type & Manufacturing method & Nano WC size $D / \mathrm{nm}$ & Micron WC size $D / \mu \mathrm{m}$ & Powder size $D / \mu \mathrm{m}$ & Nano WC rate/ $\%$ \\
\hline MP & Micro-nano & Agglomeration & $70-180$ & 2.5 & $20-53$ & 30 \\
CP & Conventional & Agglomeration & - & 1.5 & $10-45$ & - \\
\hline
\end{tabular}

Table 2 Spray parameters of WC-10Co4Cr coatings by HVOF

\begin{tabular}{lllllll}
\hline $\begin{array}{l}\text { Coating } \\
\text { No. }\end{array}$ & $\begin{array}{l}\text { Powder } \\
\text { type }\end{array}$ & $\begin{array}{l}\text { Oxygen flow } \\
\text { V/SCFH }\end{array}$ & $\begin{array}{l}\text { Fuel flow } \\
V / \text { GPH }\end{array}$ & $\begin{array}{l}\text { Gun length } \\
L / \text { inch }\end{array}$ & $\begin{array}{l}\text { Spray distance } \\
L / \mathrm{mm}\end{array}$ & $\begin{array}{l}\text { Powder feed rate } \\
M /\left(\mathrm{g} \cdot \mathrm{min}^{-1}\right)\end{array}$ \\
\hline MC & MP & 1950 & 6.5 & 6 & 370 & 75 \\
CC & CP & 1950 & 6 & 6 & 370 & 75 \\
\hline
\end{tabular}

The electrochemical performance of the coatings was measured by CorrTest electrochemical test system which mainly includes CS300 electrochemical workstation, CorrTest control and data analysis software.

\subsection{Cavitation Erosion}

Cavitation erosion tests were performed on a J93025 ultrasonic cavitation apparatus according to standard GB/T 6383-2009. The cavitation test parameters were set with a frequency of $20 \mathrm{kHz}$ and a amplitude of $40 \mu \mathrm{m} .3 .5 \mathrm{wt} \%$ $\mathrm{NaCl}$ solution at $25-28{ }^{\circ} \mathrm{C}$ was used as the test liquid in a $1000 \mathrm{~mL}$ beaker. The tip of the specimen was immersed into the water $3 \mathrm{~mm}$ deep. The schematic diagram of the $\mathrm{CE}$ test apparatus is shown in Figure 1 and specimen (its dimension is shown in Figure 2) was attached to the free end of the horn.

TG328 electronic balance with a sensitivity of $0.1 \mathrm{mg}$ was used to determine mass losses. The sample was weighed every $60 \mathrm{~min}$ and 16 measurements were carried out. The mass loss result was the average value of three specimen test and the volume loss is the mass loss divided by the material density, while cavitation rate $\left(R_{c}\right)$ is every hour volume loss. For comparison, the 316 stainless steel samples were tested under the same test conditions.

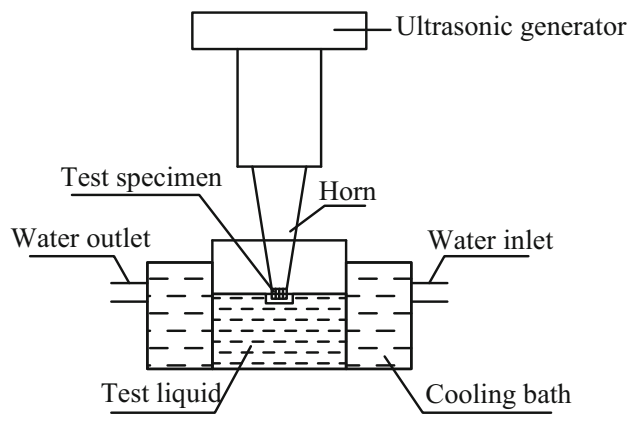

Figure 1 Schematic diagram of the CE test apparatus

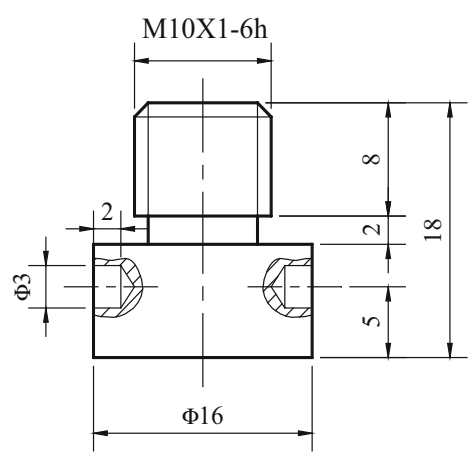

Figure 2 CE test specimen's dimensions

\section{Results and Discussion}

\subsection{Structure of WC-10Co4Cr Powders and Coatings}

The SEM micrographs of micro-nano powder (MP) and conventional $\mathrm{WC}-10 \mathrm{Co} 4 \mathrm{Cr}$ powder $(\mathrm{CP})$ are presented in Figure 3. It can be seen that both powders are highly spherical, but more pores exist at the surface of CP powder shown in Figures 3(c) and (d), demonstrating that its density is lower than MP powder. High magnification image shows micro WC particles in MP powder are wrapped by the finer nano-particles and the $\mathrm{CoCr}$ binding phase, observed in Figure 3(b).

Various structures of the as-sprayed coating surface can be observed from surface morphology of two WC$10 \mathrm{Co} 4 \mathrm{Cr}$ coatings (Figure 4) and micro-nano coating demonstrates better melting condition, less porosity and denser microstructure than the conventional one. The reason is that different structured powders can reach to different melting degrees and possess various kinetic energy during the spraying. As the micro-nano coatings consist of micron-sized and nano-sized WC with large specific surface area and high activity, a considerable portion of nanosized WC was dissolved into melted $\mathrm{CoCr}$ alloy. They 


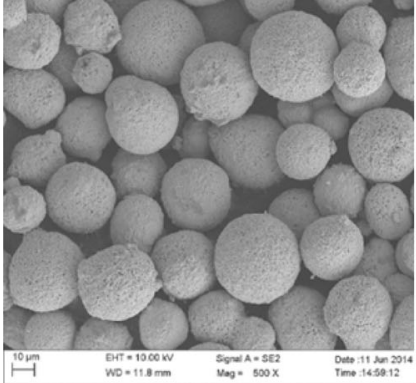

(a) MP

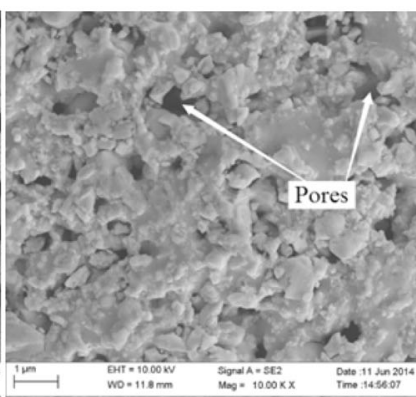

(b) MP

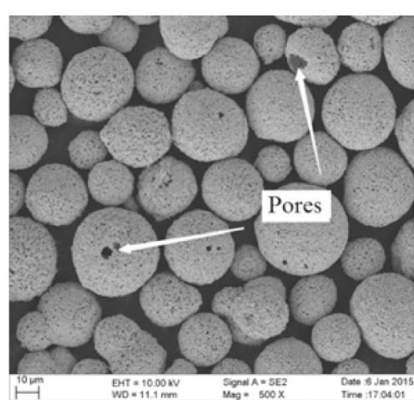

(c) $\mathrm{CP}$

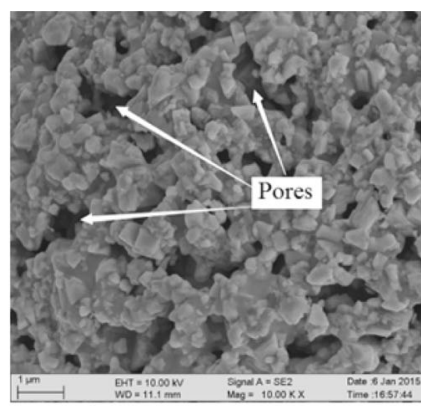

(d) $\mathrm{CP}$

Figure 3 Micrographs of WC-10Co4Cr powders at different magnification

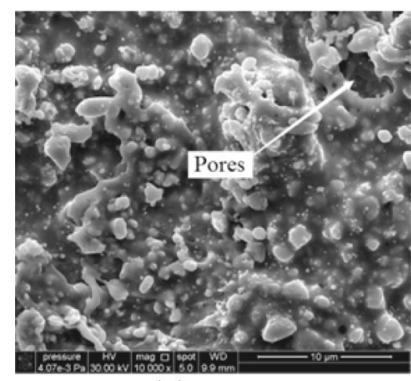

(a) $\mathrm{MC}$

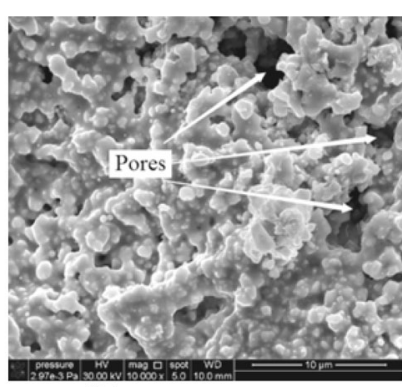

(b) $\mathrm{CC}$
Figure 4 Surface micrographs of WC-10Co4Cr coatings

would fill in un-molten or semi-molten micro WC particles, forming the micro-nano structure, shown in Figure 4(a).

The cross-sectional microstructures of the micro-nano and conventional $\mathrm{WC}-10 \mathrm{Co} 4 \mathrm{Cr}$ coatings are shown in Figure 5. No obvious porosity can be observed from the low magnification micrographs (Figures 5(a) and (c)) for two HVOF sprayed coatings and the porosity is both less than $0.5 \%$ (Table 3 ). Moreover, the porosity of micro-nano coating is smaller $(0.26 \pm 0.07 \%)$, which is $39.5 \%$ lower than that of the conventional one, since the gap between micro WC particles was filled with dissolved nano WC particles and melted CoCr binding phase.

It can be observed that the nano, submicron and micron sized WC particles exist in micro-nano WC-10Co4Cr coating (Figure 5(b)), while in conventional coating only the submicron and micron sized WC particles can be observed (Figure 5(d)). The submicron sized WC particles in the micro-nano and conventional coatings were produced by the breakage of micron WC particle during the power ball mill process.

\subsection{Phase Composition of Micro-nano WC- 10Co4Cr Powders and Coatings}

Figure 6 represents the XRD results of micro-nano WC$10 \mathrm{Co} 4 \mathrm{Cr}$ powder and coating. The XRD pattern of micronano powder is mainly composed $\mathrm{WC}, \mathrm{Co}$, and $\mathrm{Co}_{3} \mathrm{~W}_{3} \mathrm{C}$ crystalline phases. $\mathrm{Co}_{3} \mathrm{~W}_{3} \mathrm{C}$ originates from insufficient carbon balance in certain area where the combination of $\mathrm{Cr}$ and $\mathrm{C}$ occurs during the sintering due to their high affinity. $\mathrm{Co}_{3} \mathrm{~W}_{3} \mathrm{C}$ phase disappears in the XRD pattern of the coating, meanwhile a small amount of $\mathrm{W}_{2} \mathrm{C}$ phase is observed. The results demonstrate that carbides are mainly composed of $\mathrm{WC}$ and a small amount of $\mathrm{W}_{2} \mathrm{C}$, while serious WC decarburization does not occur in the micronano WC-10Co4Cr coating deposited by HVOF. The XRD patterns exhibit no differences with the conventional WC$10 \mathrm{Co} 4 \mathrm{Cr}$ powder and coating analyzed by Wang in Ref. [27].

\subsection{Mechanical properties WC-10Co4Cr coatings}

Mechanical properties of $\mathrm{WC}-10 \mathrm{Co} 4 \mathrm{Cr}$ coatings sprayed by HVOF including microhardness and fracture toughness are shown in Table 3. Although the microhardness of two coatings is higher than $1300 \mathrm{HV}_{0.3}$ and obvious difference does not exist, the micro-nano coating obtains an extraordinary fracture toughness of $\sim 5.58 \mathrm{MPa} \cdot \mathrm{m}^{1 / 2}$, which is $45 \%$ higher than that of the conventional one. This outstanding property can provide obstacles to the formation and propagation of cracks during cavitation erosion.

\subsection{Electrochemical Properties of WC-10Co4Cr Coatings}

Figure 7 shows the potentiodynamic polarization curves of two WC-10Co4Cr coatings and 316 steel in $3.5 \mathrm{wt} \% \mathrm{NaCl}$ solution. It can be observed that the potentiodynamic potentials of the two coatings are below 316 steel, and micro-nano $\mathrm{WC}-10 \mathrm{Co} 4 \mathrm{Cr}$ coating possesses a higher value than the conventional one. That means the micro-nano coating has more superior electrochemical corrosion resistance due to smaller potential difference between the coating and the substrate in comparison with the conventional one. 


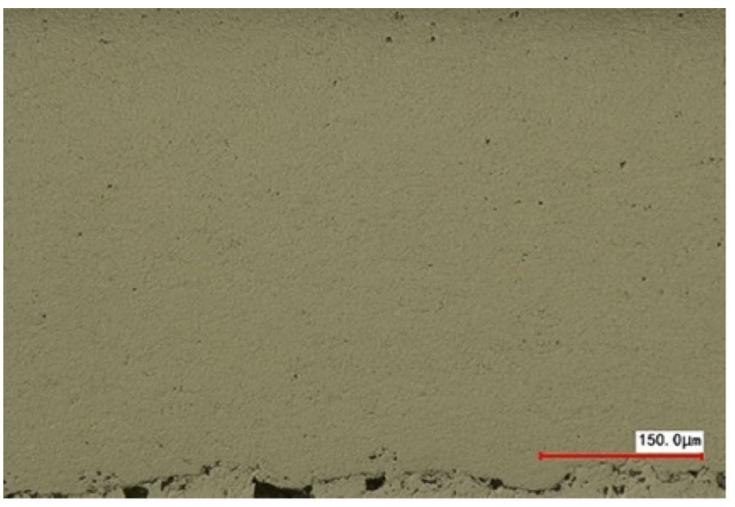

(a) $\mathrm{MC}$

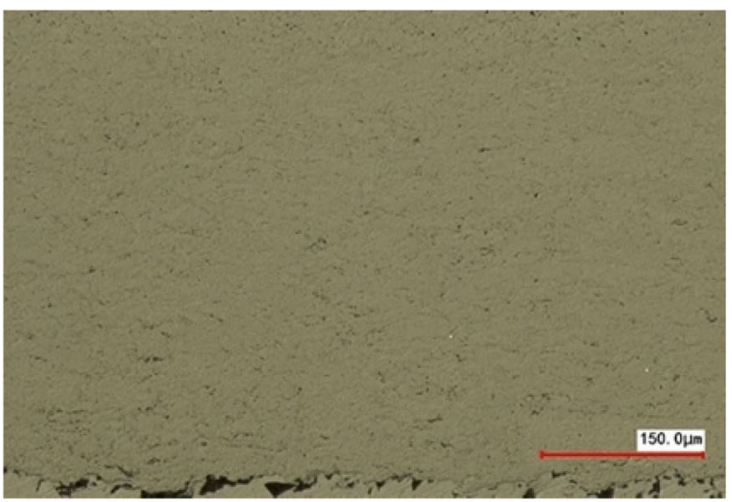

(c) $\mathrm{CC}$

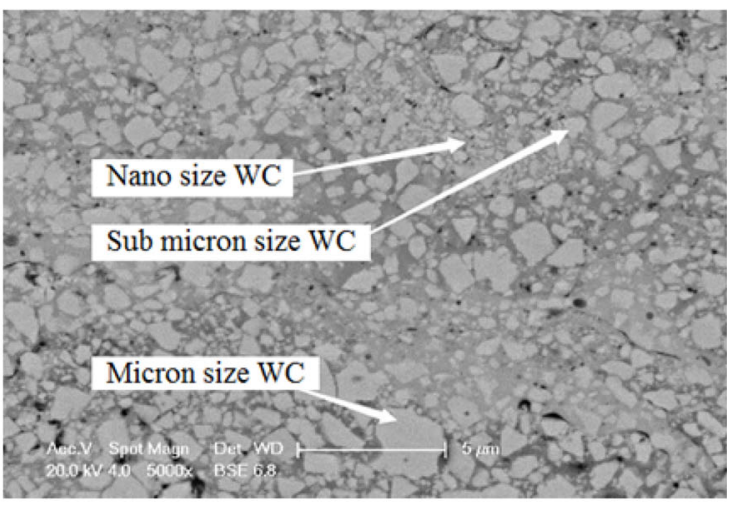

(b) MC

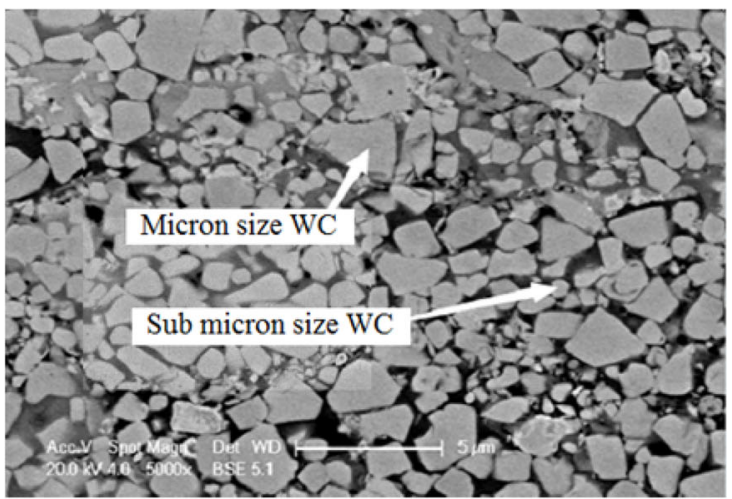

(d) $\mathrm{CC}$

Figure 5 Cross-sectional micrographs of WC-10Co4Cr coatings

Table 3 Porosity, microhardness and fracture toughness of WC$10 \mathrm{Co} 4 \mathrm{Cr}$ coatings

\begin{tabular}{llll}
\hline Specimen & $\begin{array}{l}\text { Porosity } \\
/ \%\end{array}$ & $\begin{array}{l}\text { Microhardness } \\
H V / \mathrm{MPa}\end{array}$ & $\begin{array}{l}\text { Fracture toughness } \\
K_{c} /\left(\mathrm{MPa} \cdot \mathrm{m}^{1 / 2}\right)\end{array}$ \\
\hline $\mathrm{MC}$ & $0.26 \pm 0.07$ & $1345 \pm 136$ & $5.58 \pm 0.50$ \\
$\mathrm{CC}$ & $0.43 \pm 0.12$ & $1322 \pm 181$ & $3.83 \pm 0.52$ \\
\hline
\end{tabular}

\subsection{Cavitation Erosion Test Results of WC- $10 \mathrm{Co} 4 \mathrm{Cr}$ Coatings}

Figure 8 presents the cumulative volume losses and volume cavitation rates of the two $\mathrm{WC}-10 \mathrm{Co} 4 \mathrm{Cr}$ coatings and the 316 stainless steel in $3.5 \mathrm{wt} \% \mathrm{NaCl}$ solution. Figure 8 (a) indicates that after $16 \mathrm{~h} \mathrm{CE}$, the cumulative volume losses of the micro-nano coating (MC), conventional coating $(\mathrm{CC})$ and 316 stainless steel were $2.31,3.58$ and $15.7 \mathrm{~mm}^{3}$, respectively, in which the cumulative volume losses of MC and CC decreased respectively $85 \%$ and $77 \%$ compared with 316 stainless steel. Meanwhile, the average volume cavitation rates of the micro-nano coating, conventional coating and 316 steel were respectively 0.122 ,

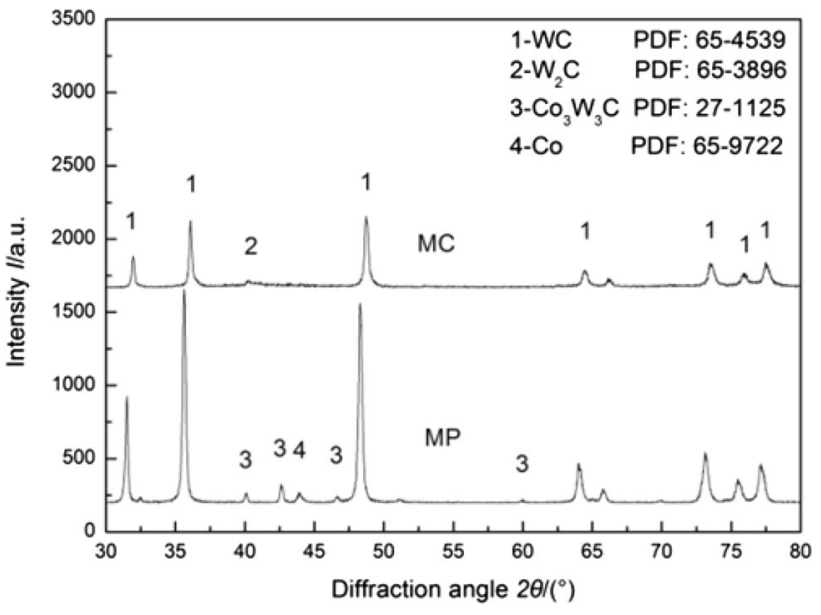

Figure 6 XRD patterns of micro-nano WC-10Co4Cr powders and coatings

0.244 and $0.972 \mathrm{~mm}^{3} / \mathrm{h}$. The cavitation rate of MC is only $50 \%$ and $12.5 \%$ as much as those of CC and 316 steel at the steady $\mathrm{CE}$ period (last $5 \mathrm{~h}$ ). From the result it can be concluded that the micro-nano $\mathrm{WC}-10 \mathrm{Co} 4 \mathrm{Cr}$ coating possesses more excellent CE resistance. 


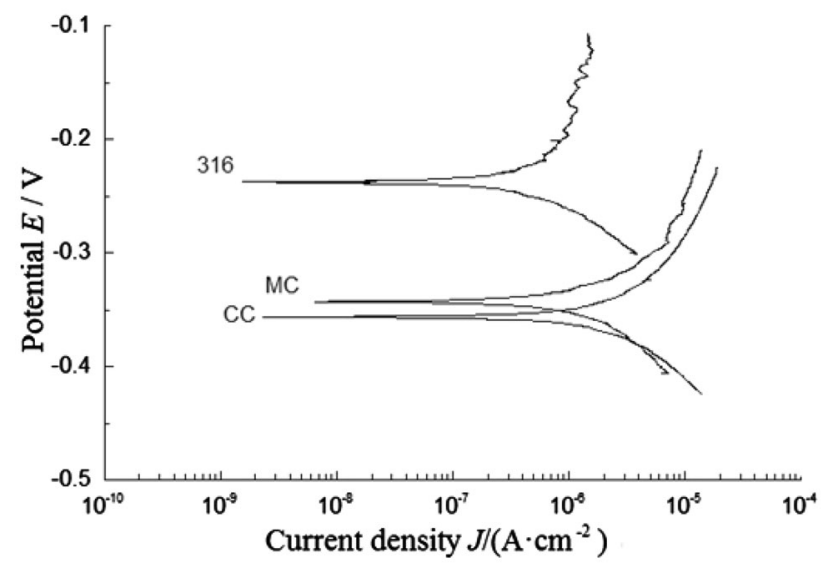

Figure 7 Tafel plots of WC-10Co4Cr coatings and 316 stainless steel

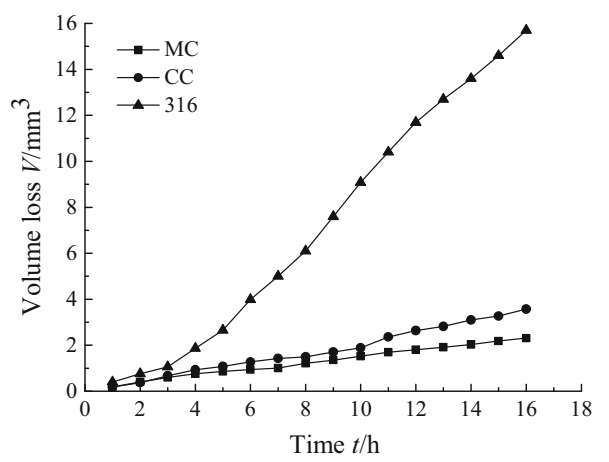

(a) Cumulative volume loss

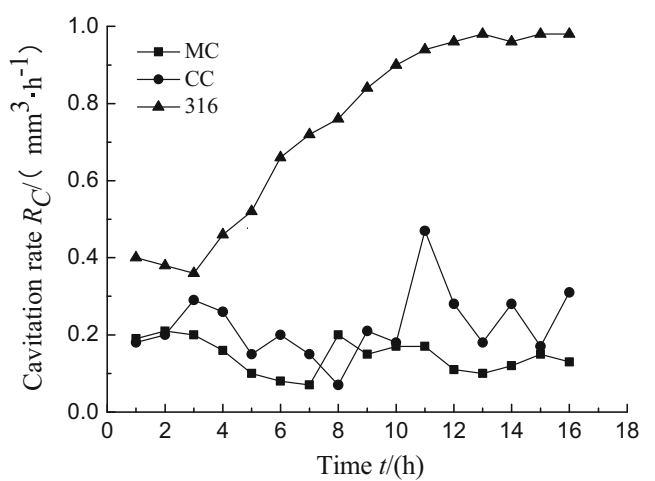

(b) Cavitation rate

Figure 8 Cumulative volume loss and cavitation rate of WC$10 \mathrm{Co} 4 \mathrm{Cr}$ coatings and 316 stainless steel in $3.5 \mathrm{wt} \% \mathrm{NaCl}$ solution

\subsection{Cavitation Mechanisms Analysis of WC- $10 \mathrm{Co} 4 \mathrm{Cr}$ Coatings}

The surface morphologies of the two WC-10Co4Cr coatings with different $\mathrm{CE}$ time at the initial period of the tests $(\leq 1 \mathrm{~h})$ are displayed in Table 4 . The dark parts in the images are the areas of the eroded coatings by CE. A small amount of pores and scratches were observed on the surface of the coatings before the test due to imperfect polishing. After $0.25 \mathrm{~h}$ CE test, $\mathrm{CE}$ appeared in the two kinds of coatings with different degree. MC coating has smaller $\mathrm{CE}$ areas than $\mathrm{CC}$ coating. After $0.5 \mathrm{~h} \mathrm{CE}$ test, the $\mathrm{CE}$ areas of the coatings expanded at different speed and the expanding speed of MC coating was slower than that of CC coating. After $1 \mathrm{~h} \mathrm{CE}$ test, the eroded area was still small on the surface of MC coating, while around $50 \%$ of CC coating area was eroded. These results are in consistence with the curves of cavitation volume loss.

$\mathrm{CE}$ was produced under the alternating stress caused by bubble generation and collapsed during ultrasonication. At the initial stage, stress concentrated at the pores and defects of the coating would accelerate the plastic deformation of the material in the vicinity. Due to the different crystal structure between WC hard phase and CoCr binding phase, deformation was not coordinated at the interface, which generated the local high stress field, and dislocation stress was accumulated at the grain boundary [27, 28]. When the cumulative stress reached the threshold, intergranular microcracks would generate and subsequently extended under repeated cycle of alternating stress, resulting in the formation of cavitation source. The cavitation source further developed along some preferable angles inside the coating [29, 30]. The formation rate of the cavitation source of the CC coating was higher at the initial stage in $3.5 \mathrm{wt} \% \mathrm{NaCl}$ solution due to its higher porosity, lower fracture toughness, and electrochemical performance. Under the stress caused by bubble collapse and the repeated impacts of micro jet along with the $\mathrm{Cl}^{-}$penetration in the solution, the further extension of cavitation cracks directly lead to the interlamination detachment and WC particles exfoliation, causing the formation of the large-scale CE. On the other hand, the low porosity of MC coating significantly reduced the amount of $\mathrm{CE}$ sources and its high hardness and toughness can effectively obstruct the extension of the CE cracks, which enables micro-nano WC-10Co4Cr coating to possess excellent $\mathrm{CE}$ resistance in 3.5 wt \% $\mathrm{NaCl}$ solution.

Figure 9 shows the SEM surface images of two coatings after $16 \mathrm{~h}$ cavitation erosion in $3.5 \mathrm{wt} \% \mathrm{NaCl}$ solution. $\mathrm{CE}$ craters with different shapes can be observed on the surface of the coatings. The surface of MC coating is just a little rough (Figure 9(a)), while CE pits with diameter more than $30 \mu \mathrm{m}$ can be observed clearly on the surface of CC coating as shown in Figures 9(b) and (c). 
Table 4 Surface micrographs of WC-10Co4Cr coatings at first period of cavitation erosion

\begin{tabular}{|c|c|c|c|c|}
\hline \multirow{2}{*}{$\begin{array}{c}\text { Coating } \\
\text { No. }\end{array}$} & \multicolumn{4}{|c|}{ CE time $t / \mathrm{h}$} \\
\hline & 0 & 0.25 & 0.5 & 1.0 \\
\hline \multicolumn{5}{|l|}{$\mathrm{MC}$} \\
\hline \multicolumn{5}{|l|}{$\mathrm{CC}$} \\
\hline
\end{tabular}

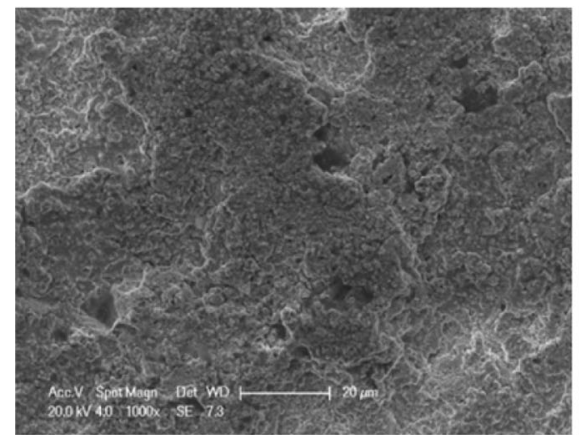

(a) $\mathrm{MC}$

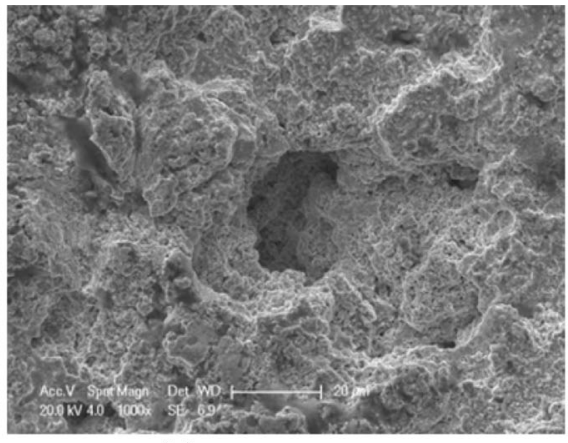

(b) $\mathrm{CC}$

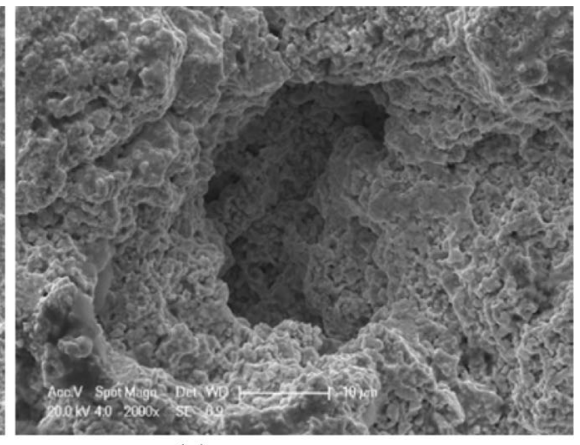

(c) $\mathrm{CC}$

Figure 9 Crater micrographs of WC-10Co4Cr coatings after $16 \mathrm{~h}$ cavitation erosion in $3.5 \mathrm{wt} \% \mathrm{NaCl}$ solution. (a) $\mathrm{MC}$, (b) $\mathrm{CC}$, (c) $\mathrm{CC}$

\section{Conclusions}

(1) In micro-nano WC-10Co4Cr coating deposited by HVOF, carbides are mainly composed of WC and with a small amount of $\mathrm{W}_{2} \mathrm{C}$, no obvious $\mathrm{WC}$ decarburization can be detected.

(2) Micro-nano WC-10Co4Cr coating exhibits better mechanical properties and its fracture toughness is $45 \%$ higher than conventional coating. Moreover, the micro-nano WC-10Co4Cr coating demonstrates higher corrosion potential and possesses better corrosion resistance.

(3) Micro-nano WC-10Co4Cr coating possesses better $\mathrm{CE}$ resistance and its $\mathrm{CE}$ resistance is enhanced above $50 \%$ than conventional coating at steady $\mathrm{CE}$ period in $3.5 \mathrm{wt} \% \mathrm{NaCl}$ solution.

(4) Superior CE resistance of HVOF sprayed micronano WC-10Co4Cr coating originates from its high hardness, high fracture toughness, low porosity and excellent corrosion resistance, which can effectively obstruct the formation and propagation of CE cracks.

Acknowledgements Supported by National Natural Science Foundation of China (Grand No. 51422507).

Open Access This article is distributed under the terms of the Creative Commons Attribution 4.0 International License (http://crea tivecommons.org/licenses/by/4.0/), which permits unrestricted use, distribution, and reproduction in any medium, provided you give appropriate credit to the original author(s) and the source, provide a link to the Creative Commons license, and indicate if changes were made.

\section{References}

1. Y Z Kehr, J H Kao. Underwater acoustic field and pressure fluctuation onshiphull due to unsteady propeller sheet cavitation. Journal of Marine Science and Technology, 2011, 16(3): 241-253. 
2. R Jasionowski, D Zasada, W Przetakiewicz. Cavitation erosion resistance of alloys used in cathodic protection of hulls of ships. Archives of Metallurgy and Materials, 2014, 59(1): $241-245$.

3. X B Zhang, C S Liu, X D Liu, et al. Cavitation erosion behavior of WC coatings on CrNiMo stainless steel by laser alloying. International Journal of Minerals Metallurgy and Materials, 2009, 16(2): 203-207.

4. L M Yang, A K Tieu, D P Dunne, et al. Cavitation erosion resistance of NiTi films produced by filtered arc deposition. Wear, 2009, 267(1-4): 233-243.

5. R Singh, S K Tiwari, S K Mishra. Cavitation erosion in hydraulic turbine components and mitigation by coatings: current status and future needs. Journal of Materials Engineering and Performance, 2012, 21(7): 1539-1551.

6. J Luo, Z B Cai, J L Mo, et al. Friction and wear properties of high-velocity oxygen fuel sprayed WC-17Co coating under rotational fretting conditions. Chinese Journal of Mechanical Engineering. 2016, 29(3): 515-521.

7. H J Kim, H S Yang, K H Baik. Development and properties of nanostructured thermal spray coatings. Current Applied Physics, 2006, 6(6): 1002-1006.

8. K S Zhou, C M Deng, M Liu, et al. Characterizations of fatigue and salt spray corrosion resistance of HVAF sprayed WC-17Co and WC-10Co4Cr coatings on the substrate of $300 \mathrm{M}$ steel. Rare Metal Materials and Engineering, 2009, 38(4): 671-676.

9. R W Armstrongr. The hardness and strength properties of WC-Co composites. Materials, 2011, 4(7): 1287-1308.

10. A Ghabchi, T Varis, E Turunen, et al. Behavior of HVOF WC$10 \mathrm{Co} 4 \mathrm{Cr}$ coatings with different carbide size in fine and coarse particle abrasion. Journal of Thermal Spray Technology, 2010, 19(1-2): 368-377.

11. N Ma, L Guo, Z X Cheng, et al. Improvement on mechanical properties and wear resistance of HVOF sprayed WC-12Co coatings by optimizing feedstock structure. Applied Surface Science, 2014, 320: 364-371.

12. S F Scieska, K Filipowicz. An integrated testing method for cermet abrasion resistance and fracture toughness evaluation. Wear, 1998, 216(2): 202-212.

13. C J Li, A Ohmori, K Tani. Effect of WC particle on the abrasive wear of thermally sprayed WC-Co coatings. Materials and Manufacturing Processes, 1999, 14(2): 175-184.

14. M G Gee, A Gant, B Roebuck. Wear mechanism in abrasion and erosion of WC/Co and related hardmetals. Wear, 2007, 263: 137-148.

15. J M Guilemany, S Dosta, J R Miguel. The enhancement of the properties of WC-Co HVOF coatings through the use of nanostructured and microstructured feedstock powders. Surface and Coatings Technology. 2006, 201(3-4): 1180-1190.

16. W Tillmann, I Baumann, P S Hollingsworth, et al. Sliding and rolling wear behavior of HVOF-sprayed coatings derived from conventional, fine and nanostructured WC-12Co powders. Journal of Thermal Spray Technology, 2014, 23(1-2): 262-280.

17. S Hong, Y P Wu, J F Zhang, et al. Ultrasonic cavitation erosion of high-velocity oxygen-fuel (HVOF) sprayed near-nanostructured WC-10Co-4Cr coating in $\mathrm{NaCl}$ solution. Ultrasonics Sonochemistry, 2015, 26: 87-92.

18. X Q Zhao, H D Zhou, J M Chen. Comparative study of the friction and wear behavior of plasma sprayed conventional and nanostructured WC-12\%Co coatings on stainless steel. Materials Science and Engineering A, 2006, 431(1-2): 290-297.

19. H Chen, G Q Gou, M J Tu, et al. Characteristics of nano particles and their effect on the formation of nanostructures in air plasma spraying WC-17Co coating. Surface and Coatings Technology, 2009, 203(13): 1785-1789.
20. A H Dent, S Depalo, S Sampath. Examination of the wear properties of HVOF sprayed nanostructured and conventional WC-Co cermets with different binder phase contents. Journal of Thermal Spray Technology, 2002, 11(4): 551-558.

21. Q Q Yang, T Senda, A Ohmori. Effect of carbide grain size on microstructure and sliding wear behavior of HVOF-sprayed WC12\% Co coatings. Wear, 2003, 254: 23-34.

22. G Skandan, R Yao, R Sadangi. Multimodal coatings: A new concept in thermal spraying. Journal of Thermal Spray Technology, 2000, 9(3): 329-331.

23. G C Ji, H T Wang, X Chen, et al. Characterization of coldsprayed multimodal WC-12Co coating. Surface and Coatings Technology, 2013, 235: 536-543.

24. Q Wang, Z H Chen, L X Li, et al. The parameters optimization and abrasion wear mechanism of liquid fuel HVOF sprayed bimodal WC-12Co coating. Surface \& Coatings Technology, 2012, 206(8-9): 2233-2241.

25. L Thakur, N Arora. A study on erosive wear behavior of HVOF sprayed nanostructured WC-CoCr coatings. Journal of Mechanical Science and Technology, 2013, 27(5): 1461-1467.

26. T Sahraoui, S Guessasma, M A Jeridane, et al. HVOF sprayed WC-Co coatings: Microstructure, mechanical properties and friction moment prediction. Materials and Design, 2010, 31(3): 1431-1437.

27. Q Wang, Z X Tang, L M Cha. Cavitation and sand slurry erosion resistances of WC-10Co-4Cr coatings. Journal of Materials Engineering and Performance, 2015, 246(6): 2435-2443.

28. S Hong, Y P Wu, J F Zhang, et al. Cavitation erosion behavior and mechanism of HVOF sprayed WC-10Co-4Cr coating in 3.5 $\mathrm{wt} \% \mathrm{NaCl}$ solution. Transactions of the Indian Institute of Metals, 2015, 68(1): 151-159.

29. Z X Ding, W Chen, Q Wang. Resistance of cavitation erosion of multimodal WC-12Co coatings sprayed by HVOF. Transactions of Nonferrous Metals Society of China, 2011, 21(10): 2231-2236.

30. S Hong, Y P Wu, J F Zhang, et al. Synergistic effect of ultrasonic cavitation erosion and corrosion of WC-CoCr and $\mathrm{FeCrSiBMn}$ coatings prepared by HVOF spraying. Ultrasonics Sonochemistry, 2016, 31: 563-569.

Xiang Ding, born in 1988, is currently a PhD candidate at State Key Laboratory of Advanced Technology for Materials and Processing, Wuhan University of Technology, China. He received his master degree from Tsinghua University, China, in 2012. His research interests include materials processing, surface engineering. E-mail: dingxiang@whut.edu.cn

Xu-Dong Cheng, born in 1954, is currently a professor and a $\mathrm{PhD}$ candidate supervisor at State Key Laboratory of Advanced Technology for Materials and Processing, Wuhan University of Technology, China. He received his $\mathrm{PhD}$ degree from Wuhan University of Technology, China, in 2000. His research interests include materials processing, surface engineering. E-mail: xdcheng54@163.com

Cheng-Qing Yuan, born in 1976, is currently a professor and a $\mathrm{PhD}$ candidate supervisor at School of Energy and Power Engineering, Wuhan University of Technology, China. He received his $\mathrm{PhD}$ degree from Wuhan University of Technology, China, in 2005. His research interests include condition monitoring and fault diagnosis, tribology and its industrial application. Email: ycq@whut.edu.cn

Jin Shi, born in 1991, is currently a master at School of Energy and Power Engineering, Wuhan University of Technology, China. He 
received his master degree on from Wuhan University of Technology, China, in 2016. E-mail: 710733845@qq.com

Zhang-Xiong Ding, born in 1961, is currently a professor at School of Energy and Power Engineering, Wuhan University of Technology,
China. He received his master degree in Wuhan University of water transportation engineering, China, in 1985. His research interests include mechanical remanufacturing, surface engineering. E-mail: zx_ding@163.com 